\title{
EFFECT OF AMBIENT HUMIDITY ON DICHOTOMOUS SAMPLER COARSE/FINE RATIOS
}

\author{
Gerald J. KeEler* \\ Department of Atmospheric and Oceanic Science, University of Michigan, Ann Arbor, MI 48109-2143, \\ U.S.A. \\ Wanda W. Brachaczek, † Robert A. Gorse, JR, Steven M. Japar and \\ William R. Pierson $\ddagger$ \\ Research Staff, Ford Motor Company, P.O. Box 2053, Dearborn, MI 48121, U.S.A.
}

(First received 30 March 1987 and in final form 1 December 1987)

\begin{abstract}
Atmospheric aerosols were measured in August 1983 on Allegheny Mountain and Laurel Hill in southwestern Pennsylvania. Ambient humidity was observed to influence the coarse to fine particle ratios as determined by dichotomous samplers. This influence is evident in the particle mass and in its component chemical species. The sampling run with the most pronounced mass shift resulted in an apparent loss of $50 \%$ of the fine mass and $66 \%$ of the fine particle sulfur to the coarse fraction. The magnitude of the mass shift appears to be related to the length of time that the aerosol was in a saturated environment and also to the original dry particle size. These observations have serious implications for receptor modeling with dichotomous sampler data whenever only the fine particles are considered.
\end{abstract}

Key word index: Aerosol, ambient humidity, saturation, meteorological forcing, dichotomous samplers, particle growth, coarse/fine ratio, size distributions, fine aerosol, coarse aerosol, XRF, NAA, sulfate, acidity, trace elements.

\section{INTRODUCTION}

The purpose of this note is to show that ambient humidity can exercise a great influence on the coarse to fine particle ratio as determined by dichotomous samplers. This influence is seen in the particle mass and in its component chemical species, and has profound implications for receptor modeling with dichotomous sampler data, especially when only the fine particles are considered. Recent trends in analyzing only the fine fraction of the measured aerosol may not be appropriate under conditions of elevated relative humidities (r.h.). The implications of these findings may also be important in the selection and use of size segregated sampling methods.

The evidence was obtained, quite by chance, in a 1month field experiment on Allegheny Mountain and Laurel Hill in southwest Pennsylvania in August 1983. Details of the experimental arrangement are discussed in other publications (Japar et al., 1986; Pierson et al., $1986,1987)$ and will not be recapitulated here. The dichotomous samplers were Sierra Model 245, with

\footnotetext{
* Author to whom correspondence should be addressed. Present address: Harvard School of Public Health, 665 Huntington Avenue, Boston, MA 02115, U.S.A.

$\uparrow$ Present address: Dearborn, MI 48124, U.S.A.

$\ddagger$ Present address: Energy and Environmental Engineering Center, Desert Research Institute, P.O. Box 60220, Reno, NV 89506, U.S.A.
}

coarse/fine cutpoint diameter $2.5 \mu \mathrm{m}$ when operated at the $1 \mathrm{~m}^{3} \mathrm{~h}^{-1}$ flow rate for which the units are designed. Each unit had an inlet designed to exclude particles larger than $15 \mu \mathrm{m}$ (first half of the experiment) or $10 \mu \mathrm{m}$ (second half of the experiment) diameter. The particles were collected on Teflon membrane filters and analyzed gravimetrically and by $\mathrm{X}$ ray fluorescence and neutron activation analysis.

Products of gas-to-particle conversion are expected to be primarily in the fine fraction. These products, such as $\mathrm{SO}_{4}^{2-}$, are generally found to have average coarse to fine mass concentration ratios less than 0.1 (i.e. less than $10 \%$ coarse). On the other hand, elements derived from soil, such as $\mathrm{Al}$ or $\mathrm{Si}$, tend to be found in the coarse particle fraction, with coarse to fine ratios greater than 3.0 (i.e. greater than $75 \%$ coarse). The effect of atmospheric humidity on aerosol particle size is well documented (Junge, 1963; Charlson et al., 1974a,b). Aerosol particles are known to deliquesce to form droplets at high r.h., thus influencing the size distribution.

Figure 1 shows the coarse to fine concentration ratio for selected elements and aerosol mass measured at Allegheny Mountain. The ratios are plotted on a log scale with the elements shown in order of increasing mean particle size, starting with $\mathbf{S}$, which is greater than $90 \%$ fine on average, and ending with samarium, which has $15 \%$ of its mass in the fine fraction on average. The time-weighted average coarse to fine ratio for each element and for mass is indicated as a horizontal line. It is apparent that large swings 

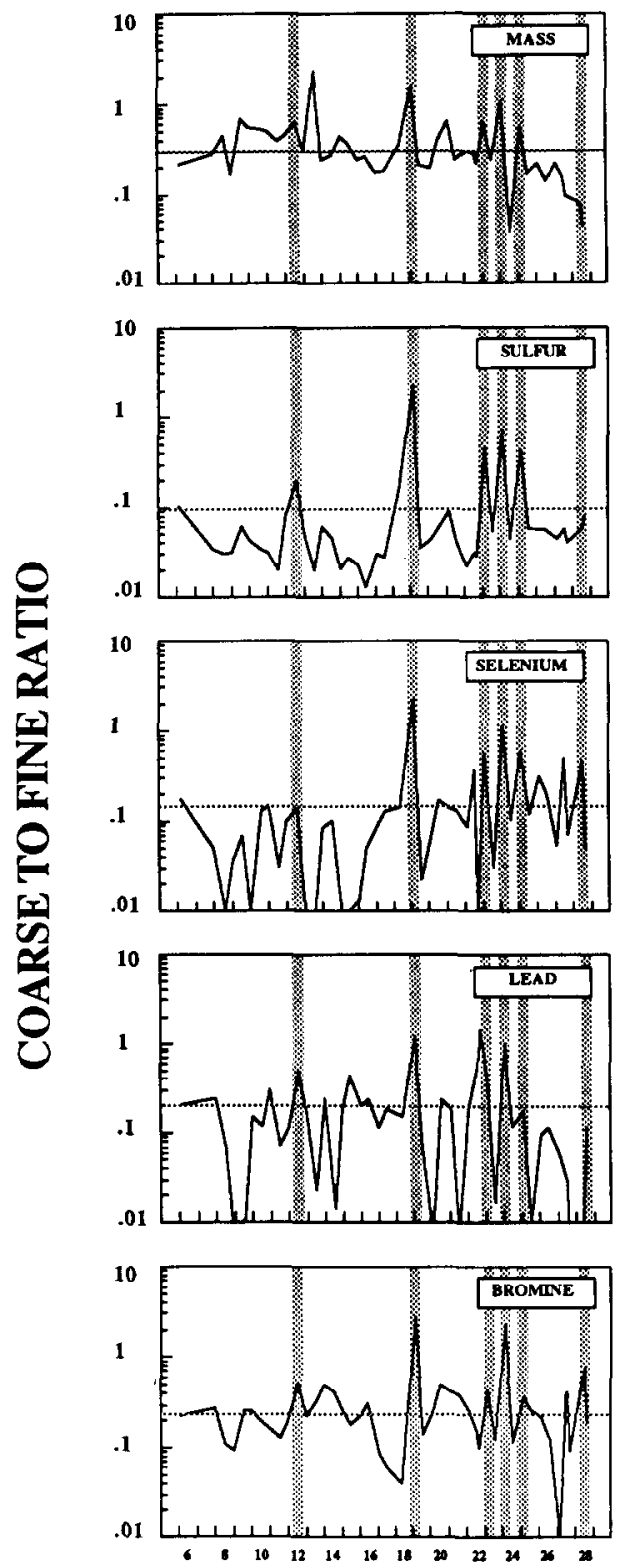

DATE IN AUGUST
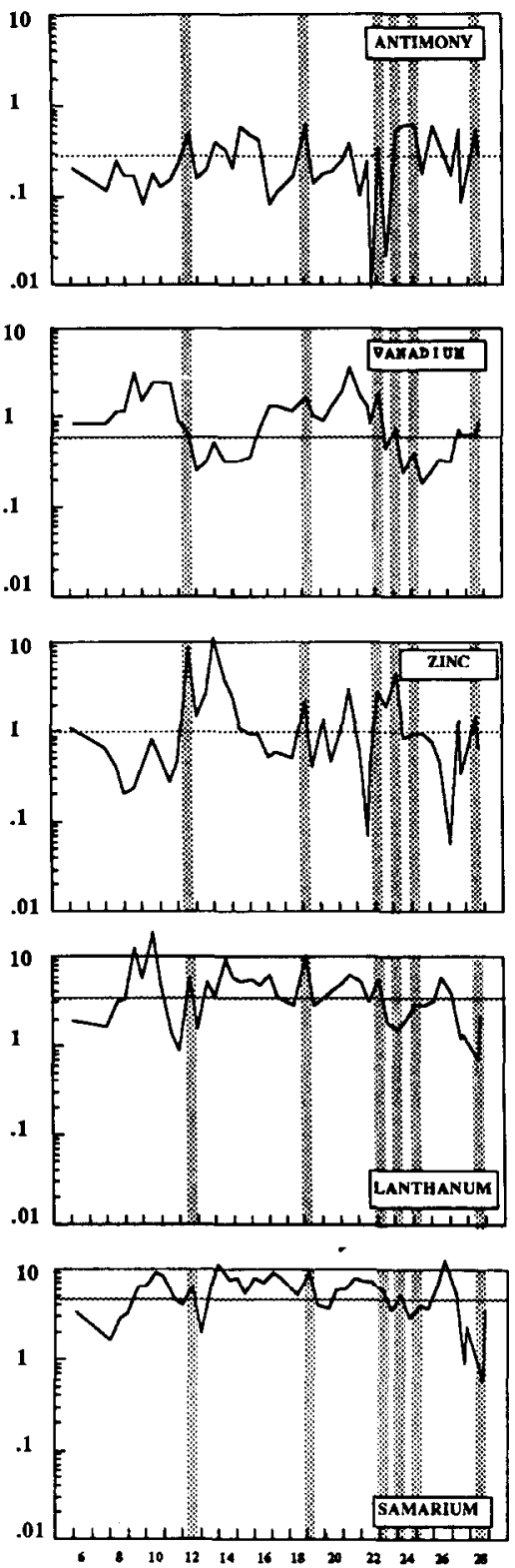

DATE IN AUGUST

Fig. 1. Coarse to fine concentration ratios at Allegheny Mountain. Ratios are plotted on a log scale with the elements shown in order of increasing mean particle size, starting with $S$ and ending with $\mathrm{Sm}$. The timeweighted average coarse to fine ratio for each element and for mass is indicated as a horizontal line. The shaded vertical lines indicate runs in which the r.h. was $100 \%$ for at least half the sampling time.

in the coarse to fine ratio can occur for many elements and that the maxima in the ratio tend to occur at the same time for several elements. Those sampling runs which displayed peaks in their ratio for multiple elements can be explained by examining the concurrent meteorological information, specifically the relative humidity and wind speed.

In Fig. 1, those runs at Allegheny in which the relative humidity was equal to $100 \%$ for at least $50 \%$ of the run are designated by shaded vertical lines. In fact, all but one of the runs so designated correspond to runs in which visual observations of cloud or fog at the Allegheny Mountain site were reported. Coarse filters from the dichotomous samplers were also noted as being wet for each of the designated runs, except the last one in the month. The filters being wet can cause complications of inhomogeneous loadings on the filter, making XRF analysis more difficult and the results more uncertain. At the runs designated by shading, peaks are seen in the coarse/fine ratio, signifying transfer of fine particulate mass into the coarse particle mode; this transfer is especially evident in the case of $S$ and Se. The runs marked by shaded lines, however, were not the only ones in which fine particu- 
late mass appears to have been transferred into the coarse mode. Sampling runs which did not show as pronounced an effect on as many elements or display as large a percentage shift in the individual element's fine mass were not at saturation (i.e. not at r.h. $=100 \%$ ) for as large a fraction of the sample duration as the shaded runs. A relationship between the percentage of sampling time at saturation and the magnitude of the mass shift into the coarse mode is apparent. Lindberg et al. (1979) reported a similar relationship involving fine particle mode $(<0.45 \mu \mathrm{m})$ species $\mathrm{Zn}, \mathrm{Mn}, \mathrm{Cd}, \mathrm{Pb}$ and $\mathrm{SO}_{4}^{2-}$ vs the water vapor content in the atmosphere. They found that the duration of radiation fog was negatively correlated with the fine particle mode concentrations. A similar relationship was reported by Meszaros (1968) between the r.h. and the relative contribution of water soluble $\mathrm{SO}_{4}^{2-}$ particles in the Aitken size range to the total aerosol $\mathrm{SO}_{4}^{2-}$ concentration. It was suggested that the inverse relationship revealed the submicrometer particles to be hygroscopic, thus increasing in size as the r.h. increased. Samson and Keeler (1986) also saw evidence for an inverse relationship between atmospheric r.h. and the measured fine particle mass concentrations of $\mathrm{S}, \mathrm{Zn}, \mathrm{As}, \mathrm{Se}$ and $\mathrm{Pb}$, at a site in the Shenandoah Valley of Virginia.

Lindberg and Harriss (1983) noted that the $\mathrm{pH}$ of the atmospheric aerosol can influence the solubility of the aerosol-associated metals. At low $\mathrm{pH}$, insoluble metal compounds can be converted by acid attack into relatively soluble $\mathrm{SO}_{4}^{2-}$ and $\mathrm{NO}_{3}^{-}$salts. Probably more important at Allegheny, where the metals were a very minor part of the aerosol chemical composition generally, is the fact that $\mathrm{H}_{2} \mathrm{SO}_{4}$ and its $\mathrm{NH}_{4}^{+}$salts are all hygroscopic, and in particular $\mathrm{H}_{2} \mathrm{SO}_{4}$ forms a wellknown series of stable hydrates, $\mathrm{H}_{2} \mathrm{SO}_{4} \cdot x \mathrm{H}_{2} \mathrm{O}$ ( $x=0,1,2,4)$, which renders $\mathrm{H}_{2} \mathrm{SO}_{4}$ a strong absorber of water. Thus, the $\mathrm{pH}$ enhancement may have had an influence at both Allegheny and Laurel since the aerosols measured were very acidic, with a mean $\mathrm{H}^{+} / \mathrm{SO}_{4}^{2-}$ mole ratio of 1.0 .

The same coarse-to-fine ratio plot constructed using data from the Laurel Hill site is shown in Fig. 2. The frequency of saturation was lower at Laurel Hill than at Allegheny Mountain. Thus, only four sampling periods are marked by shaded vertical lines, which again indicate saturation conditions for more than $50 \%$ of the sampling run. Three of the four sampling periods at Laurel indicated as being at $100 \%$ r.h. for $>50 \%$ of the time correspond to concurrent runs at Allegheny Mountain which were also at $100 \%$ r.h. for $>50 \%$ of the time. All four of these sampling periods at Laurel resulted in wetness being observed on the dichotomous sampler coarse filters.

In general, the shifting of mass from one mode to another is less pronounced at Laurel than at Allegheny; but why is this? There is no significant altitude difference between the two sampling sites (Laurel is approximately $12 \mathrm{~m}$ higher), and the sites are separated by only $35.5 \mathrm{~km}$. It may be instructive to look more closely at the meteorological conditions during a sampling run in which the apparent mass shift was observed at both sites.

The sampling run which commenced on the night of 18 August was chosen for closer investigation, as it was found to have the most pronounced mass shift at both sites. A surface high pressure area dropped down out of Canada into northern Ohio prior to the sampling period being discussed. At the start of the sampling run, the center of the high was located approximately over the Cleveland area. Large areas of haze and fog were reported at NWS surface stations to the east of the high. Winds were out of the northwest making the Allegheny site directly downwind of the Laurel site. As the high migrated towards the southeast the region of fog and haze also moved in that general direction. The chemical compositions of the aerosol measured at the sites were not significantly different for this period and yet the mass shift was more pronounced at Allegheny. One explanation for this would be that the aerosol reaching Allegheny was in a saturated environment for a longer period of time than the aerosol collected at Laurel. The meteorological conditions and the observed chemical compositions at the two sites would certainly support this hypothesis. The r.h. was $100 \%$ at the Allegheny site for the entire sampling period while the Laurel site was at saturation for roughly half of the time. The percentage of mass shifted into the coarse fraction for each element and for particulate mass is given in Table 1 for both sites. The percentage change given is defined as the percentage of mass which apparently shifted using the time-weighted mean coarse to fine ratio as the reference. The percentage change in each species at Allegheny Mountain was greater than or equal to the percentage change at Laurel Hill for this sample. The difference between sites was also more pronounced for the typically fine fraction elements, $\mathrm{S}, \mathrm{Se}, \mathrm{Pb}$, etc. This pattern was similar for the other runs when the sites were both at saturation.

The mass shift from the fine to the coarse mode on the night of the 18 th can also be seen in a comparison of the $\mathrm{SO}_{4}^{2-}$ concentrations from the other measurement techniques employed at Allegheny Mountain. The $\mathrm{SO}_{4}^{2-}$ concentration determined from the denuder-difference apparatus, which had a $1.5 \mu \mathrm{m}$ cutoff inlet, was $426 \mathrm{neq} \mathrm{m}^{-3}$. The $\mathrm{SO}_{4}^{2-}$ concentration as determined from analysis of the $142 \mathrm{~mm}$ Teflon filter, which had a $10 \mu \mathrm{m}$ cutoff, was 820 neq $\mathrm{m}^{-3}$. Therefore, approximately half of the $\mathrm{SO}_{4}^{2-}$ was unable to pass the $1.5 \mu \mathrm{m}$ cutoff inlet. The two measurement techniques did not see such a large difference in $\mathrm{SO}_{4}^{2-}$ concentration for any other sampling run.

As was stated earlier, meteorology is not the only factor affecting the coarse to fine concentration ratio measured at a site. The sources of the measured aerosol can also be an important factor. Anthropogenically derived particles in the atmosphere tend to be mainly in the fine particle size range, whereas natural sources, such as soil, tend to contribute larger par- 

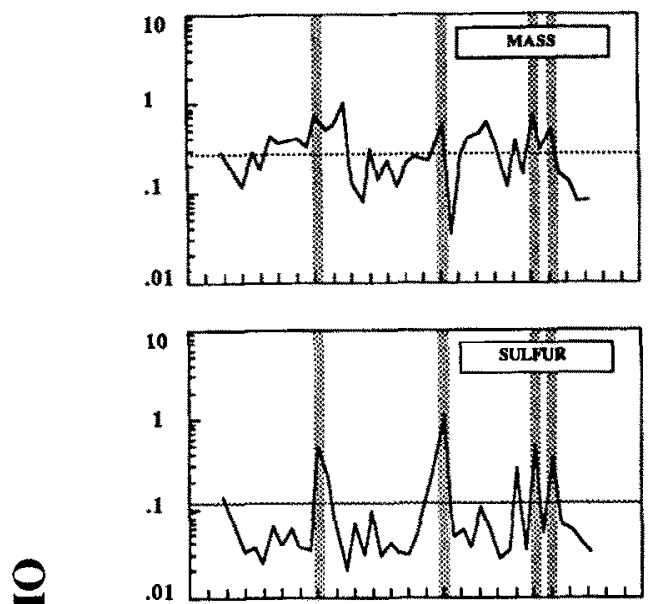

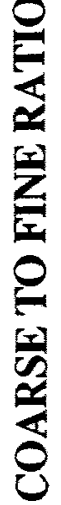
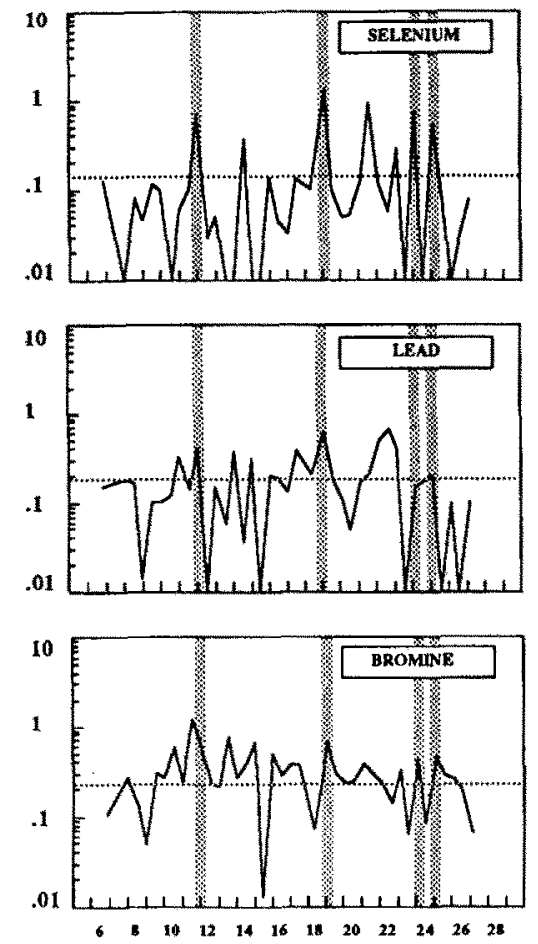

DATE IN AUGUST
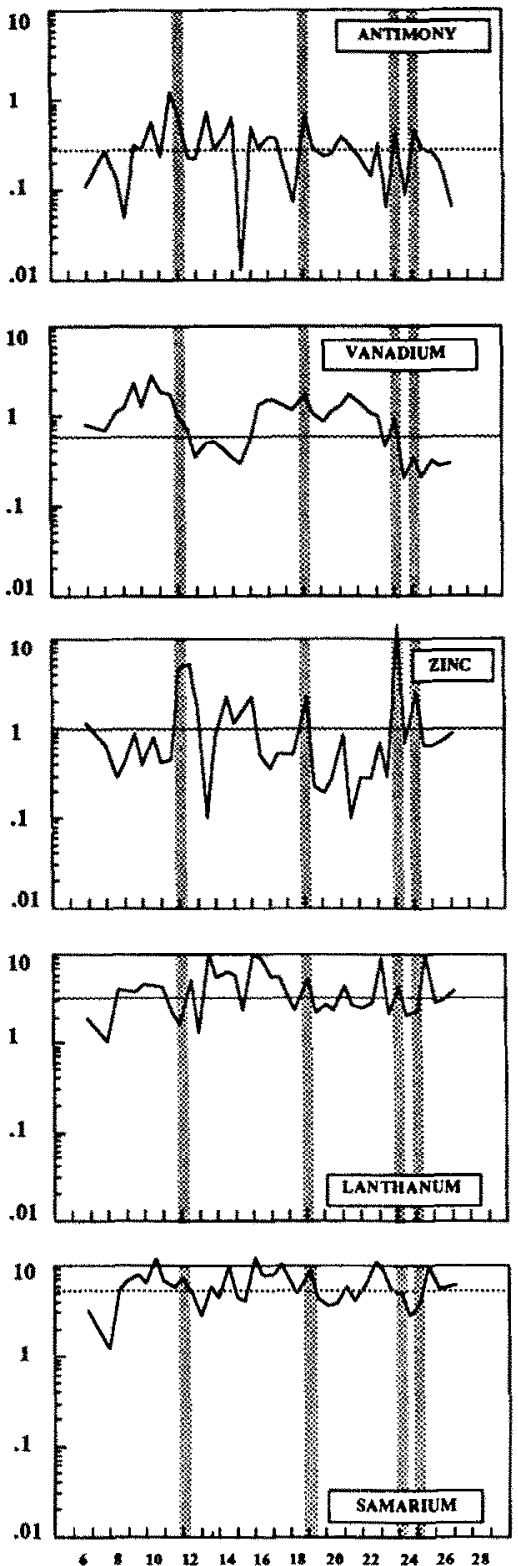

DATE IN AUGUST

Fig. 2. Coarse to fine concentration ratios at Laurel Hill. Ratios are plotted on a log scale with the elements shown in order of increasing mean particle size, starting with $\mathbf{S}$ and ending with $\mathrm{Sm}$. The time-weighted average coarse to fine ratio for each element and for mass is indicated as a horizontal line. The shaded vertical lines indicate runs in which the r.h. was $100 \%$ for at least half the sampling time.

ticles. In those sampling periods at both sites that were found to have coarse to fine ratios that exceeded the time-weighted average ratio, not all of the high ratios could have been due to humidity effects. The period 12-15 August was found to have several runs with a higher than average coarse to fine ratio. This period was an exceptionally clean period for the eastern U.S. as the winds were consistently from the northeast in response to flow around the back side of a low pressure system that had moved off the coast. The winds at the surface and throughout the mixed layer were also relatively strong during this 2-3 day period, enhancing the coarse particle element concentrations relative to the fine-particle elements. This can be seen by looking at those elements which are typically coarse fraction elements such as $\mathrm{La}$ and $\mathrm{Sm}$.

\section{AEROSOL. GROWTH OR SAMPLING ARTIFACT?}

In the foregoing discussion, alteration of the coarse/fine concentration ratios was attributed to 
Table 1. Percentage of fine mode shifted due to humidity

\begin{tabular}{lcc}
\hline \multicolumn{3}{c}{ Measurement site } \\
Species & Allegheny Mountain & Laurel Hill \\
\hline Mass & & \\
\hline $\mathrm{S}$ & $50 \%$ & $27 \%$ \\
$\mathrm{Se}$ & $66 \%$ & $46 \%$ \\
$\mathrm{~Pb}$ & $63 \%$ & $51 \%$ \\
$\mathrm{Br}$ & $45 \%$ & $26 \%$ \\
$\mathrm{Sb}$ & $39 \%$ & $11 \%$ \\
$\mathrm{~V}$ & $21 \%$ & $9 \%$ \\
$\mathrm{Zn}$ & $7 \%$ & $6 \%$ \\
$\mathrm{La}$ & $36 \%$ & $36 \%$ \\
$\mathrm{Sm}$ & $63 \%$ & $36 \%$ \\
\hline
\end{tabular}

Elements are listed in order of increasing observed mean particle diameter.

particle growth rather than sampling artifacts for three reasons. First, coarse and total flow rates were recorded several times during each sampling period and there was no significant deviation from the proper 1:10 coarse to total flow ratio during the runs in question. Thus, a reduction in flow due to plugging of the fine filter under prolonged saturated conditions was not evident. Furthermore, wetness was only observed on the coarse fraction filters. Plugging or restriction in flow to the coarse filters would have decreased the coarse/fine ratio and would have caused an effect opposite to that observed. Second, as mentioned above, $\mathrm{SO}_{4}^{2-}$ analyses from filter samplers with significantly different aerosol cut points show much higher loadings on filters behind $10 \mu \mathrm{m}$-cutpoint inlets than on those behind $1.5 \mu \mathrm{m}$-cutpoint inlets. Finally, total mass concentrations (fine plus coarse mass) observed concurrently at Deep Creek Lake (C. Lewis, U.S. EPA, Personal Communication, 1987), located approximately $60 \mathrm{~km} \mathrm{SSW}$ of the Allegheny site, were almost identical to those measured at Allegheny Mountain and Laurel Hill, while a significant fine mass shift was not observed, apparently the result of lower r.h. encountered at Deep Creek Lake; 6-h average r.h. never exceeded $80 \%$.

\section{CONSEQUENCES OF THE MASS SHIFT}

It is apparent from the previous discussion that large shifts in elemental mass from the fine mode into the coarse can take place in the atmosphere under saturated conditions. The consequences of this meteorological forcing could be dramatic in terms of receptor modeling results. If a receptor model, such as a Chemical Mass Balance model, did not explicitly take into account the influence of atmospheric moisture effects, it would certainly be unable to account for the observed mass of individual elements in each size fraction. It also becomes clear that simply taking the coefficient of fractionation, $\alpha$, to be unity will prevent the receptor model from apportioning the elemental concentrations correctly. Changes in the size distributions of aerosol particles would also mean changes in the deposition velocities of these particles (Hänel, 1982), ultimately leading to $\alpha$ being anything but unity.

The implications of these findings may also be important in the selection and use of size segregated sampling methods. In particular, recent trends in analyzing only the fine fraction of the measured aerosol may not be appropriate. In more mountainous areas, where the frequency of saturated conditions is higher, care must be exercised in sampling aerosols. Using only the fine fraction data, it would be unlikely that a receptor model would account correctly for the measured mass of individual elemental species.

Acknowledgements-We are pleased to acknowledge the assistance of the Pennsylvania Turnpike Commission in providing access and electrical power to the two sites and helping us set up the experiment: we are especially indebted to Warren E. Kipp, Robert E. Davis, Nevin A. Miller, Carl Baker and the crew at the Allegheny Mountain Tunnel, and the Chief Engineer and Deputy Executive Director of the Pennsylvania Turnpike Commission, Robert H. Klucher. We are indebted to Karen M. Adams, James W. Butler, Ann C. Cleary, James C. Dziadosz, Larry P. Haack, I homas. J. Korniski, Fred E. McKelvy, Joseph M. Norbeck, William K. Okamoto, and Michael J. Rokosz, all of Ford, and Jeffrey $\mathbf{M}$. Masters, formerly of the University of Michigan, for their participation in the field experiment. Also participating in the field experiment were E. Eugene Weaver (retired from Ford) and Adele Weaver. Finally, we thank Robert K. Stevens of EPA/ESRL for providing the $10-\mu \mathrm{m}$ inlets. Our work was supported in part by the National Science Foundation under Industry/University Cooperative Research Grant No. ATM8507282 to the University of Michigan.

\section{REFERENCES}

Charlson R. J., Vanderpol A. H., Covert D. S., Waggoner A. P. and Ahlquist N. C. (1974a) $\mathrm{H}_{2} \mathrm{SO}_{4} /\left(\mathrm{NH}_{4}\right)_{2} \mathrm{SO}_{4}$ background aerosol: optical detection in the St. Louis region. Atmospheric Environment 8, 1257-1267.

Charlson R. J., Vanderpol A. H., Covert D. S., Waggoner A. P. and Ahlquist N. C. (1974b) Sulfuric acid-ammonium sulfate aerosol: optical detection in the St. Louis region. Science 184, 156-161.

Hänel G. (1982) Influence of relative humidity on aerosol deposition by sedimentation. Atmospheric Environment 16, 2703-2706.

Japar S. M., Brachaczek W. W., Gorse R. A., Jr, Norbeck J. M. and Pierson W. R. (1986) The contribution of elemental carbon to the optical properties of rural atmospheric aerosols. Atmospheric Environment 20, 1281-1289.

Junge C. E. (1963) Air Chemistry and Radioactivity. Academic Press, New York.

Lindberg S. E. and Harriss R. C. (1983) Water and acid soluble trace elements in atmospheric particles. J. geophys. Res. 88, 5091-5100.

Lindberg S. E., Harriss R. C., Turner R. R., Shriner D. S. and Huff D. D. (1979) Mechanisms and rates of atmospheric deposition of selected trace elements and sulfate to a deciduous forest watershed. Rep. ORNL/TM-6674, Oak Ridge Natl Lab., Oak Ridge, TN.

Meszaros E. (1968) On the size distribution of water soluble particles in the atmosphere. Tellus 20, 443-448. 
Pierson W. R., Brachaczek W. W., Gorse R. A., Ir, Japar S. M. and Norbeck J. M. (1986) On the acidity of dew. J. geophys. Res. 91, 4083-4096.

Pierson W. R., Brachaczek W. W., Gorse R. A., Jr, Japar S. M., Norbeck J. M. and Keeler G. J. (1987) Acid rain and atmospheric chemistry at Allegheny Mountain. Envir. Sci. Technol. 21, 679-691.

Samson P. J. and Keeler G. J. (1986) Meteorological analysis of trace element data. EPA Final Report, Washington, D.C. 